\title{
Obituary for Dr. Anna Celler
}

\author{
Arman Rahmim ${ }^{1,2} \cdot$ Carlos Uribe $^{1,2} \cdot$ Alex MacKay $^{1} \cdot$ Glenn Wells $^{3}$
}

Published online: 13 May 2021

(C) The Author(s), under exclusive licence to Springer-Verlag GmbH Germany, part of Springer Nature 2021

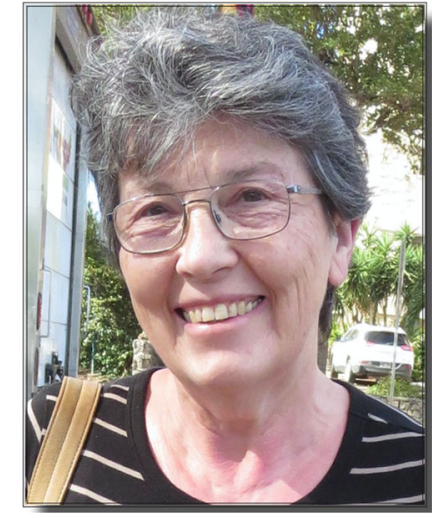

Dr. Anna Celler, a fantastic colleague, mentor, educator, and pioneer in medical imaging, passed away on December 24, 2020.

Born and raised in 1951 in Poland, Dr. Celler received her M.Sc. in 1974 and her Ph.D. in 1980 from the University of Warsaw where she became an expert in nuclear physics. After spending some time in research laboratories in Poland, France, and Finland, she moved to Canada with her husband and joined the Charge Exchange Group at TRIUMF in 1984. In 1991, Anna joined the nuclear medicine department at the Vancouver General Hospital as a clinical medical imaging physicist. Soon, she was overseeing the quality assurance program of 12 nuclear medicine departments around the Lower Mainland. In 1995, Anna was certified as a member of the Canadian College of Physicists in Medicine (CCPM) in

This article is part of the Topical Collection on Editorial

Picture used with permission from the Cellar family.

\footnotetext{
Arman Rahmim

arman.rahmim@ubc.ca

University of British Columbia, Vancouver, BC, Canada

2 BC Cancer, Vancouver, BC, Canada

3 University of Ottawa Heart Institute, Ottawa, ON, Canada
}

recognition of her competence in physics as applied to medicine. She became a fellow of the CCPM one year later.

Dr. Celler's passion for research led her to create the Medical Imaging Research Group (MIRG) in 1991 at the Vancouver General Hospital (VGH)/University of British Columbia (UBC). Her research interests were related to image quantification with diagnostic nuclear medicine imaging modalities, particularly with single photon emission computed tomography (SPECT). Anna is considered a pioneer in quantitative and dynamic SPECT, as well as a leading expert in dosimetry for radiopharmaceutical therapies using SPECT. As an example, Siemens implemented a "profile attenuation correction system" in their medical equipment which was a method fully developed by Anna. In 2012, Anna received the Sylvia Fedoruk prize for her work in dual isotope imaging with positron emission tomography (PET). Dr. Celler was also part of a multi-institutional and multi-disciplinary team led by researchers at TRIUMF (Canada's national particle accelerator center) that developed methods of producing the isotope Tc-99 $\mathrm{m}$ with a cyclotron. This method received Health Canada's approval in early December 2020 and will make it possible to avoid shortages of this radioisotope which is used in more than $80 \%$ of all nuclear medicine diagnostic procedures. This work was awarded the Brockhouse Canada Prize for Interdisciplinary Research in Science and Engineering in 2015. Anna's work has also found multiple applications in the development of personalized patient dosimetry for radiopharmaceutical therapies.

Over the last 3 decades, Dr. Celler supervised numerous trainees in medical physics. She supervised post-doctoral fellows, graduate students, undergraduate students, and nuclear medicine residents. Most of her trainees have now leading positions in academia, industry, and healthcare.

Because of all her contributions to clinical duties, teaching, and research, Dr. Celler was awarded the Gold Medal of the Canadian Organization of Medical Physicists (COMP) in 2018, the highest distinction given by this organization.

What stood out profoundly with Anna was that she valued human beings. She cared deeply about her trainees and the people around her, and created and led a lively work and research environment. She will be tremendously missed. 


\section{Declarations}

Ethical approval Not applicable

Conflict of interest The authors declare no competing interests.

Publisher's note Springer Nature remains neutral with regard to jurisdictional claims in published maps and institutional affiliations. 